I Università degli Studi di Genova, Departamento de Scienze

della Formazione, Gênova, GE, Itália

iafet.leonardibricalli@edu.unige.it

https://orcid.org/oooo-ooor-5517-6925

lafet Leonardi Bricalli

\title{
A VIGILÂNCIA COMO CULTURA
}

Lyon, David. (2018).

The culture of surveillance: watching as a way of life.

Cambridge: Polity Press.

No imaginário social, a vigilância segue identificada à figura do Big Brother, o personagem que tudo vê do romance 1984 (Orwell, 2008). A metáfora orwelliana da vigilância projeta a imagem de um olhar externo, geralmente opressor, destinado a não deixar qualquer margem à liberdade dos indivíduos e que guarda muita semelhança com o modelo panóptico da vigilância, criticamente analisado por Foucault (2009), a partir dos escritos do filósofo utilitarista Jeremy Bentham.

Em The culture of surveillance, David Lyon - diretor do Centro de Estudos de Vigilância e professor de sociologia da Queen's University, em Kingston, Ontário, Canadá, que se ocupa do tema da vigilância há mais de 30 anos - mostra que pensar a vigilância do século XXI nos termos orwellianos se mostra, se não necessariamente errado, ao menos profundamente equivocado.

A tese defendida no livro é de que a vigilância do século XXI caracteriza-se pela participação ativa dos indivíduos na própria vigilância. A vigilância se tornou parte de todo um modo de vida e por isso a utilização do termo cultura. Ao contrário do entendimento da vigilância como algo externo, imposto a nós, a vigilância como parte da cultura se irradia pela sociedade e torna-se algo que os cidadãos comuns aceitam (conscientemente ou não), negociam, se envolvem, desejam ou mesmo resistem. O que antes era um aspecto institucional de disciplina e controle social da modernidade, hoje está internalizado, constitui uma parcela das reflexões diárias e das práticas cotidianas dos cidadãos comuns. 
O livro é estruturado em três partes e dividido em seis capítulos. A primeira, "Culture in context", é formada pelo capítulo inicial, "Crucibles of culture", em que o autor fornece as pistas conceituais das quais dependerá o restante do livro. A cultura da vigilância deve ser entendida no interior de um movimento maior da modernidade, com a emergência do que Zigmunt Bauman denomina modernidade líquida (a vigilância é uma de suas variações e foi tema de publicação que apresenta um diálogo de Bauman (20I3) com Lyon). A modernidade líquida confunde-se com a era digital e nasceu de um significante deslocamento cultural (relacionado à mudança do mundo do trabalho e da produção para o mundo do consumo) que substitui disciplina e controle por desempenho. Obediência, lei e obrigação convivem e muitas vezes são substituídos pelo apoio à liberdade e aos desejos.

O conceito de cultura da vigilância não descreve uma situação unificada. Abrange desde aspectos dos imaginários de vigilância, construídos pela nossa exposição contínua a filmes, séries, livros, reportagens, câmeras, controles biométricos etc., que não nos deixam nunca esquecer de que a vigilância é uma fato da vida moderna, até aspectos das práticas de vigilância, a nossa contribuição para o desenrolar de uma vida ligada à vigilância, que pode ser tanto de envolvimento (instalação de câmeras em residências ou veículos, registro de situações cotidianas a partir de smartphones e uso de mídias sociais para vigilância de ou- tros ou de si mesmo) quanto de resistência (proteção criptografada de dados pessoais na internet, uso de vestuários que limitam o reconhecimento por câmeras, rejeição de uso de cartões fidelidade etc.). Trata-se, portanto, de um conceito guarda-chuva, que objetiva reunir diferentes manifestações de um modo de vida ligado à vigilância, cujos efeitos, ainda, variam de acordo com o tipo de sociedade e dependem de variáveis como classe, raça e gênero. O uso do conceito de cultura da vigilância se justifica posto que objetiva distinguir-se dos conceitos de Estado de vigilância e sociedade de vigilância, que já não são adequados ao século XXI, pois partem do pressuposto da vigilância como algo exercido a partir de um ponto externo. Ambos, portanto, são insuficientes em dar conta de como os cidadãos atualmente se engajam de modo ativo na vigilância.

A segunda parte do livro, "Cultural currents", contém os capítulos dois, três e quatro. O dois, "From convenience to compliance", ilustra a maneira como o caráter ubíquo da vigilância contribui para moldar um imaginário social que naturaliza a vigilância - e alimenta suas práticas -, que por sua vez alimenta os imaginários, num movimento circular. O autor mostra, por exemplo, como práticas de vigilância de aeroportos contribuem para criar insegurança, ansiedade e medo, particularmente sobre grupos sociais já estigmatizados, como o dos árabes. Destaca ainda, um tipo de vigilância mais sutil, que é o tratamento de dados por parte de re- 
des de varejo, que podem ser usados para construção de perfis de usuários visando moldar políticas de marketing ou definir acesso a melhores condições de pagamento. As pessoas, por sua vez, respondem intencionalmente à vigilância, organizando suas vidas em torno dela, protegendo suas casas e os membros de sua família ou checando o que os seus parceiros ou crianças estão fazendo.

O capítulo três, "From novelty to normalization", aborda o modo como os imaginários e as práticas da vigilância se relacionam com a atração exercida pelas tecnologias. Exemplos: reconhecimento facial como jogos em aplicativos ou no Facebook; design de smartphones; as smartcities; e o uso, voluntário ou não, de sensores nos corpos e nos vestuários para medir desempenhos individuais. A parte final do capítulo é muito importante, pois Lyon mostra como a criação de perfis a partir do cruzamento dos dados da vigilância podem ser instrumentos de classificação social. Baseada na gestão de riscos e oportunidades, tal classificação pode determinar a quem se deve destinar bens e serviços ou quem deve ser considerado suspeito ou criminoso. Isso pode afetar acessos a serviços de saúde, crédito, segurança social, educação e opções de emprego

O capítulo quatro, "From online to onlife", ilustra o campo em que a cultura da vigilância talvez melhor se manifeste: as atividades online diárias, particularmente nas mídias sociais. Como o próprio título do capítulo sugere, hoje é praticamente impossível separar a vida online da vida offline, uma vez que os dispositivos de rede estão embebidos no ambiente vivido e são partes das interações cotidianas. Nas mídias sociais assistir aos outros é parte da história, mas tornar-se visível é a outra parte. Trata-se de uma vigilância sobre si mesmo, uma busca constante de aperfeiçoamento e desempenho, uma concorrência a si mesmo e aos outros, motivada por busca de pertencimento e adequação, e reveladora de narcisismo. A "virada participatória", ou seja, quando são os próprios indivíduos que se revelam sem a necessidade de uma participação externa, ocorre dentro de uma mudança político-econômica de um complexo de "vigilância-industrial" em que a vigilância era vista como algo mau, para um complexo de "vigilância-inovação”, em que ela é considerada uma força para o bem.

A terceira parte do livro, "Co-creation: culture, ethics, politics", é formada pelos capítulos cinco e seis. O cinco, "Total transparency", objetiva trazer para a discussão os temas explorados nos capítulos anteriores à luz de um romance intitulado $O$ círculo, escrito por Dave Eggers. Segundo Lyon, o livro é paradigmático na ilustração do que o autor entende por vigilância no século XXI, assim como I 984 o foi para a vigilância do século XX. O "Big Brother está assistindo você" muda para "Tudo o que acontece deve ser conhecido'. O livro é uma metáfora do imperativo da transparência que comanda todos os aspectos da vida cotidiana de todos os cidadãos comuns e representa uma distopia que, ao contrário do caráter sombrio de I984, possui contornos su- 
aves mas nem por isso menos preocupantes, ao evidenciar a padronização de estilos, a aversão ao diferente, ao estrangeiro, ao Outro.

No capítulo seis, "Hidden hopes", Lyon pretende fugir de abordagens deterministas segundo as quais nada pode ser feito para deter as forças políticas e econômicas globais que moldam a cultura da vigilância, pois, segundo o autor, a ação humana nunca é restrita aos códigos da cultura dominante. É uma tentativa de encontrar brechas na cultura da vigilância de modo a utilizá-la de modo positivo. Nas palavras de Lyon, uma vigilância para os outros e não sobre os outros. Como o fundamental da vigilância do século XXI é a participação ativa dos indivíduos, então isso exige um olhar autorreflexivo para nossas próprias vontades e desejos de assistir, registrar e exibir nossas vidas e a dos outros. Resistir à vigilância não é apenas encontrar meios de se proteger da vigilância (privacidade), mas encontrar maneiras de canalizar a vigilância para aspectos de cuidado, atenção e proteção do outro.

The culture of surveillance possui o mérito de enxergar a importante mudança de paradigma que a vigilância experimentou no século XXI. Embora David Lyon reconheça em diversas passagens do texto que essa cultura foi e é moldada por forças políticas e econômicas, ele as associa à mudança do mundo do trabalho e da produção para o mundo do consumo, mas sem explicar como efetivamente atuam essas forças. Quando o autor cita os papéis do desejo, da performance e do desempenho para explicar a cultura da vigilância em sua forma mais característica, as atividades online diárias nas mídias sociais, faltou explicitar que a captura das subjetividades é justamente uma das dimensões mais importantes do capitalismo contemporâneo (Dardot \& Laval, 20I4). Em outras palavras, não basta dizer que a vigilância funciona a partir de nós; é preciso enfatizar como o capitalismo funciona a partir de nós, uma abordagem que traz ainda novos elementos para se pensar o que significa, de fato, capitalismo de vigilância (Zuboff, 20I5), conceito que se limita à previsão e modificação do comportamento humano e ao tratamento econômico dos dados produzidos pelos usuários.

Recebida em I4/3/2020 | Aprovada em 2I/7/2020 


\section{REFERÊNCIAS BIBLIOGRÁFICAS}

Bauman, Zygmunt. (2013). Vigilância líquida: diálogos com David Lyon. Rio de Janeiro: Zahar.

Dardot, Pierre \& Laval, Christian. (2016) [2009]. A nova razão do mundo: ensaio sobre a sociedade neoliberal. São Paulo: Editora Boitempo.

Foucault, Michel. (2009) [1975]. Vigiar e punir: história da violência nas prisões. Petrópolis: Vozes.

Orwell, George. (2005) [1949]. I984. São Paulo: Companhia Editora Nacional.

Zuboff, Soshana. (2015). Big other: surveillance capitalism and the prospects of an information civilization. Journal of Information Technology, 30, p. 75-89.

Iafet Leonardi Bricalli é doutorando em sociologia pela Università degli Studi di Genova, Itália. É licenciado, bacharel e mestre em geografia pela Universidade Federal do Espírito Santo (UFES). É coautor com Cláudio Zanotelli de Vigilância urbana: os paradoxos da utilização de câmeras em espaços públicos da cidade de Vila Velha - ES, e autor de The paradoxes in the use of the panopticon as a theoretical reference in urban video-surveillance studies: a case study of a CCTV system of a Brazilian city e de $O$ governo da insegurança nas cidades brasileiras contemporâneas: um exercício de análise à luz das contribuições de Michel Foucault sobre os poderes e suas espacialidades. 